\title{
ESTUDO gUÍMICO DE ALIMENTOS FORMULADOS À BASE DE PALMITO Bactris gasipaes H.B.K. (PUPUNHA) DESIDRATADO ${ }^{1}$
}

\author{
Marlene Azevedo Magalhães MONTEIRO ${ }^{2, *}$, Paulo César STRINGHETA², \\ Dilson Teixeira COELHO², Josefina Bressan Resende MONTEIRO ${ }^{3}$
}

\section{RESUMO}

O coração da palmeira Bactris gasipaes H.B.K. (pupunha) foi utilizado, sob forma desidratada, na formulação de uma sopa-creme para merenda escolar. Análises químicas do palmito e do coração da palmeira (açúcares redutores, lipídeos, proteínas totais, aminograma, fibras, calorias e minerais) foram feitas tanto na forma in natura como na forma processada, bem como na de sopa-creme. Não foram encontradas diferenças relevantes em relação a essas determinações, podendo-se ressaltar a boa qualidade aminoacídica do coração da palmeira.

Palavras-chave: palmito; desidratação; análise química; alimentos formulados.

\section{SUMMARY}

CHEMICAL STUDY OF FORMULATED FOODS BASED ON DEHYDRATED Bactris gasipaes H.B.K. (PUPUNHA).Utilization of the byproduct of processing of Bactris gasipaes was studied using a commercial dehydration process (cream-soup) intended for school snacks. In order to assess its performance, chemical analyses for both the hearts of palm and the palm stipes were carried out. The chemical compositions of the palm stipes did not show higher nutrient yields in relation to the hearts of palm and neither there were differences in the per-cent, mineral or amino acid composition.

Keywords: heart of palm; dehydration; chemical analyses; processed foods.

\section{1 - INTRODUÇÃO}

Como alimento, o palmito é conhecido desde épocas remotas, ocupando lugar de destaque não só na culinária brasileira como na estrangeira, graças principalmente ao "flavor" e "sui-generis" que apresenta [9].

A constante e crescente necessidade de suprimento de matéria-prima para as indústrias no mercado nacional e internacional tem despertado especial interesse em outros gêneros da família Palmae, particularmente aqueles capazes de fornecer palmito de boa qualidade e a curto prazo. Além disso, o aproveitamento de outras partes da palmeira também tem sido estudado, como o coração, geralmente desprezado pelas indústrias. O coração da palmeira é a porção da palmeira que se situa abaixo do palmito, medindo aproximadamente de 10 a $20 \mathrm{~cm}$, formado por estruturas apicais do estirpe. Dentre as espécies atualmente estudadas destaca-se a Bactris gasipaes, também conhecida como pupunha, nativa da região Amazônica, a qual foi introduzida na Costa Rica, onde é cultivada em condições racionais, com finalidade de obtenção tanto do palmito como de seus frutos, os quais são de alto valor nutritivo, ricos em carboidratos e vitamina A [4].

A grande vantagem do pupunha Bactris gasipaes é que a palmeira não apresenta espinhos, atinge idade de corte de dois e meio aos três anos de idade, produzindo palmito de 1.200g a 1.300g [4, 5]. Esta palmeira também se destaca pelas características de precocidade, rusticidade e capacidade de perfilhamento. O palmito pro-

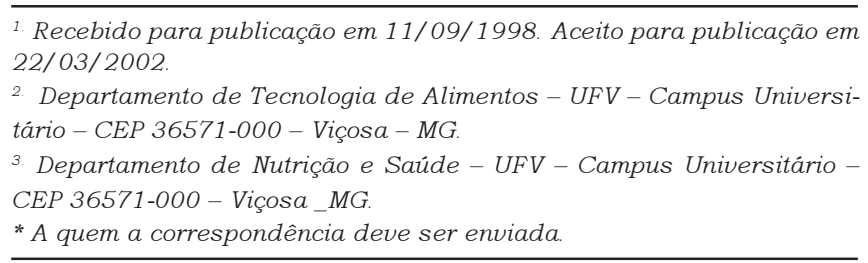

duzido por esta planta, embora com características diferentes das espécies Euterpe, tradicionalmente utilizadas para produção é bem aceito sensorialmente [5].

O coração da palmeira, apesar de apresentar na composição mineral valores menores do que no palmito, não deve ser desprezado como alimento [6].

Este trabalho tem como objetivo realizar análises químicas (açúcares redutores, lipídeos, proteinas totais, aminograma, fibras, calorias e minerais) no palmito e coração da palmeira na forma in natura, processada, e sopa-creme.

\section{2 - MATERIAL E MÉTODOS}

\section{1 - Matéria-prima}

As amostras de palmito e coração da palmeira pupunha in natura foram obtidas na região de São Mateus (Espírito Santo), cedidas pela Empresa COIMEX AGRÍCOLA S/A. O palmito processado foi adquirido da mesma empresa.

As amostras in natura totalizaram 65 lotes, de idade entre 18 a 24 meses de campo. Para as amostras em conserva utilizaram-se 18 vidros de palmito e 27 de coração da palmeira, com peso líquido drenado de $350 \mathrm{~g}$.

\section{2 - Preparo da matéria-prima}

A palmeira pupunha, por ocasião do corte, tinha em torno de 18 a 24 meses de idade e oito cascas envolvendo o tolete. Foi feito o desbaste total dos toletes e, estes conduzidos até a linha de processamento. O critério para avaliação da aproveitabilidade do palmito e do coração da palmeira baseou-se na resistência por eles oferecida ao corte, quando suave pressão era exercida no produto por meio de uma faca de aço inoxidável, e na sua ausência de podridão nas pontas. 


\section{3 - Processamento}

O processamento foi feito pela empresa COIMEX AGRICOLA S/A, de acordo com o fluxograma mostrado na Figura 1.

\section{4 - Avaliação química}

As amostras de $50 \mathrm{~g}$ cada uma foram retiradas aleatoriamente de várias regiões dos toletes. Após determinação de umidade, as amostras foram desidratadas para posterior determinação de açúcares redutores e carboidratos totais, proteína bruta, aminograma, lipídeos, minerais, fibras e calorias, cujos métodos serão descritos no item 2.7 .

\section{5 - Desidratação do palmito e do coração da pal- meira pupunha}

Para a desidratação, fatiou-se manualmente o palmito e o coração da palmeira processados com o auxílio de facas de aço inoxidável. Para ambas as partes da palmeira, a secagem foi feita em estufa FANEM a $45-50^{\circ} \mathrm{C}$, permanecendo aí até que o produto chegasse a uma umidade final de 3-5\%. Após a desidratação, armazenou-se o produto em embalagens plásticas, para posterior trituração em liquidificador doméstico.

\section{6 - Formulações}

Preparou-se uma formulação-padrão para sopa cremosa de palmito e, em seguida substiuiu-se o palmito pelo coração da palmeira. Foram acrescentados outros ingredientes, como a maltodextrina e o leite em pó, para proporcionar alto valor energético e boa qualidade protéica à sopa-creme. A farinha de trigo foi substituída pelo amido de milho, a fim de dar uma textura mais cremosa à sopa. Os demais ingredientes (salsinha, cebolinha, cebola e alho desidratados) foram acrescentados, para tornar a sopa mais saborosa e atraente ao consumidor (Tabela 1). Utilizou-se ainda uma pequena percentagem de palmito em pedaços (em ambas as sopas), a fim de dar ao comensal maior satisfação ao degustar a sopa-creme. A sopa desidratada de palmito e coração da palmeira foi armazenada em sacos plásticos de polietileno $(20 / 35 \mathrm{~cm})$, à temperatura de refrigeração.

2.7 - Análises químicas do palmito e do coração da palmeira in natura e processados e da sopa preparada com palmito e com coração da palmeira

As amostras analisadas foram: palmito in natura, coração da palmeira in natura, palmito processado, coração da palmeira processado, sopa de palmito e sopa de coração da palmeira.

As amostras foram desidratadas em estufa FANEM com temperatura entre 45 e $50^{\circ} \mathrm{C}$ por 8,6 horas, para $\mathrm{O}$ palmito, e 14 horas, para o coração da palmeira. A seguir foram trituradas em liquidificador e, no material triturado, foram feitas as análises de açúcares redutores, aminograma, fibras e calorias. As análises de açúcares, proteinas e lipídeos foram realizadas pelo Centro de Pesquisas Especiais - CEPE/BH, a do aminograma, pelo Laboratório de Análise de Alimentos do Departamento de Alimentos e Nutrição Experimental/Faculdade de Ciências Farmacêuticas/USP, e as de minerais, fibras e calorias, pelo Laboratório de Nutrição Animal do Departamento de Zootecnia/UFV.

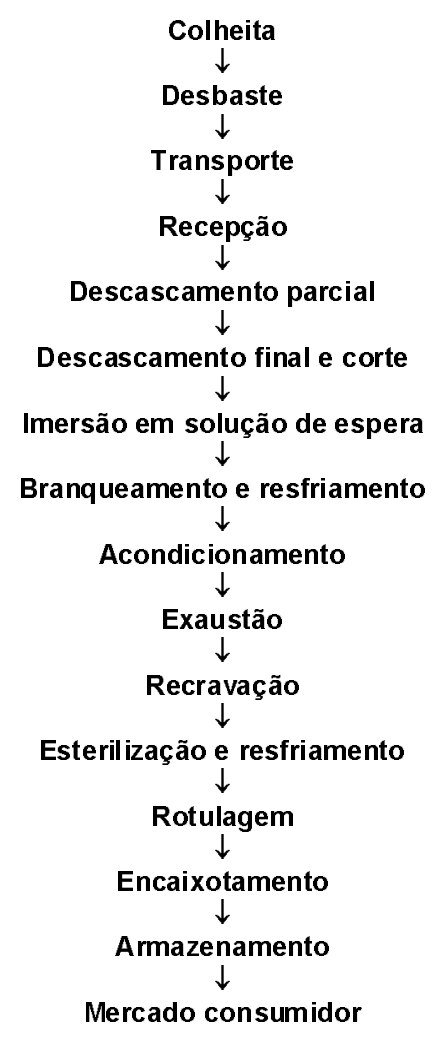

FIGURA 1. Fluxograma das etapas de processamento do palmito enlatado, segundo NOGUEIRA [9].

TABELA 1. Ingredientes da sopa de palmito e da sopa de coração da palmeira desidratadas

\begin{tabular}{lcc}
\multicolumn{1}{c}{ Componentes } & Sopa de palmito (\%) & Sopa de coração (\%) \\
\hline Maltodextrina & 5,0 & 5,0 \\
Amido de milho & 15,0 & 15,0 \\
Palmito em pó & 25,0 & - \\
Coração de palmeira em pó & - & 25,0 \\
Palmito desidratado em pedaços & 8,0 & 8,0 \\
Gema de ovo desidratada & 8,0 & 8,0 \\
HPP* (sabor frango) & 3,0 & 3,0 \\
Creme de leite (pó) & 20,0 & 20,0 \\
Leite em pó integral & 10,0 & 10,0 \\
Salsinha desidratada & 0,3 & 0,3 \\
Cebolinha desidratada & 0,2 & 0,2 \\
Cebola desidratada & 0,5 & 0,5 \\
Alho desidratado & 1,0 & 1,0 \\
Sal & 4,0 & 4,0 \\
\hline
\end{tabular}

* Hydrolized plant protein

Os métodos utilizados para cada análise são descritos a seguir. 
a) Umidade: O método utilizado foi o gravimétrico [10].

b) Proteína bruta: foi determinada pelo método de Kjeldah1 [1].

c) Aminograma: utilizou-se a cromatografia de troca iônica.

d) Lipideos: foram determinados por extração com éter etílico em extrator contínuo de Soxhlet [10].

e) Açúcares redutores: foram determinados pelo método de Fehling [10].

f) Fibras totais: foram determinadas pelo método enzimático-gravimétrico [2].

g) Minerais: os minerais ferro, cálcio, magnésio, manganês, sódio, potássio, cobre e zinco foram determinados por espectrofotometria de absorção atômica [1], e o fósforo, colorimetricamente [1].

h) Calorias: foram determinadas em bomba calorimétrica PARR do tipo adiabática.

\section{3 - RESULTADOS E DISCUSSÃO}

\section{1 - Formulações}

A formulação-base utilizada no preparo da sopa-creme foi obtida após diversos testes, variando-se as percentagens de cada ingrediente. Esta formulação proporcionou ao produto uma textura de creme, de aspecto e sabor agradável.

Os componentes da sopa-creme de palmito ou coração da palmeira foram escolhidos de forma a proporcionar a esta alto valor energético e boa qualidade protéica (Tabela 1).

Outro aspecto é o valor calórico da sopa-creme de coração da palmeira $(388,8 \mathrm{kcal}$ por $100 \mathrm{~g}$ de produto desidratado) em relação ao valor calórico de sopas desidratadas $(364,0$ kcal) segundo a Tabela de Composição de Alimentos, de acordo com o Estudo Nacional da Despesa Familiar (Tabela 2) [7]. Pode-se verificar que o valor calórico obtido nesta formulação de sopa de coração é semelhante à Tabela do ENDEF [7].

TABELA 2. Valor calórico do palmito e coração in natura e processados, sopa-creme de palmito e de coração da palmeira

$\begin{array}{lc} & \text { Valor calórico (kcal/g) } \\ \text { Palmito sem processamento } & 3,437 \\ \text { Palmito com processamento } & 3,423 \\ \text { Sopa-creme de palmito } & 3,988 \\ \text { Coração sem processamento } & 3,644 \\ \text { Coração com processamento } & 3,498 \\ \text { Sopa-creme de coração } & 3,888\end{array}$

Outro fator importante é a quantidade mínima da calorias $(350,0 \mathrm{kcal})$ e proteínas $(9, \mathrm{Og})$ que a merenda escolar deve conter diariamente [3]. Esse valor é atingido, em média, com três conchas médias de sopa de coração da palmeira preparada na diluição 1:9.

\section{2 - Características químicas}

Os resultados da composição química do palmito e a do coração da palmeira pupunha ao natural, processado e sob forma de sopa-creme são descritos a seguir.

TABELA 3. Composição química do palmito e do coração da palmeira in natura

\begin{tabular}{lcc}
\hline \multicolumn{1}{c}{ Determinações } & Palmito & Coração da palmeira \\
\hline Açúcares redutores (\% de MS) & 8,03 & 15,82 \\
Proteína bruta (\% de MS) & 18,70 & 12,83 \\
Lipídeos (\% de MS) & 0,45 & 0,31 \\
Fibras totais (\% de MS) & 20,93 & 28,00 \\
Umidade & 91,52 & 90,14 \\
\hline
\end{tabular}

MS = Matéria-seca

Não houve diferenças relevantes entre o palmito e o coração da palmeira in natura (Tabela 3) e os processados (Tabela 4). Na forma in natura os teores de açúcares redutores e fibras totais foram superiores no coração da palmeira, enquanto que para lipídeos e umidade praticamente foram iguais. Para o palmito e coração da palmeira processados, os resultados foram semelhantes aos descritos na forma in natura, exceto o teor de lipídeos e proteina, que foi maior para o coração da palmeira processado.

TABELA 4. Composição química do palmito e do coração da palmeira processados

\begin{tabular}{lcc}
\hline \multicolumn{1}{c}{ Determinações } & Palmito & Coração da palmeira \\
\hline Açúcares redutores (\% de MS) & 9,02 & 15,57 \\
Proteína bruta (\% de MS) & 24,12 & 11,07 \\
Lipídeos (\% de MS) & 2,73 & 4,07 \\
Fibras totais (\% de MS) & 26,70 & 37,56 \\
Umidade & 84,37 & 88,82 \\
\hline
\end{tabular}

MS = Matéria-seca

De acordo com a Tabela 5, a composição química das sopas de palmito e coração praticamente mantevese igual à do palmito e coração processados, exceto as fibras que tiveram redução em ambas as partes.

TABELA 5. Composição química da sopa-creme de palmito e da sopa-creme de coração da palmeira

\begin{tabular}{lcc}
\hline \multicolumn{1}{c}{ Determinações } & Palmito & Coração da palmeira \\
\hline Açúcares redutores (\% de MS) & 18,16 & 18,42 \\
Proteína bruta (\% de MS) & 17,40 & 15,86 \\
Lipídeos (\% de MS) & 3,52 & 3,29 \\
Fibras totais (\% de MS) & 9,41 & 12,97 \\
Umidade & 89,86 & 91,12 \\
\hline
\end{tabular}

MS = Matéria-seca

Na Tabela 6 é mostrada a composição em aminoácidos do coração da palmeira in natura e da sopa de coração da palmeira. Esta composição em aminoácidos indica a potencialidade da proteina, mas não revela, obrigatoriamente, que um aminoácido em particular seja utili- 
zado pelo organismo. Vale salientar que a diferença no perfil de aminoácidos entre o coração da palmeira in natura $(77,74)$ e a sopa de coração da palmeira $(89,81)$ foi devida à presença de outras fontes protéicas, como a gema de ovo, na sopa.

TABELA 6. Composição em aminoácidos do coração da palmeira in natura e da sopa creme de coração da palmeira pupunha

\begin{tabular}{lcccc}
\hline \multirow{2}{*}{ Aminoácidos } & \multicolumn{2}{c}{ Coração da palmeira in natura } & \multicolumn{2}{c}{ Sopa de coração da palmeira } \\
\cline { 2 - 5 } & $\begin{array}{c}\text { Média } \\
\text { (gaa/100g de ptn) }\end{array}$ & Desvio padrão & $\begin{array}{c}\text { Média } \\
\text { (gaa/100g de ptn) }\end{array}$ & Desvio padrão \\
\hline Cisteína & -- & -- & -- & - \\
Aspártico & 25,34 & 0,70 & 9,48 & 2 valores \\
Treonina & 2,86 & 0,06 & 3,90 & 0,06 \\
Serina & 3,84 & 0,09 & 3,95 & 0,10 \\
Glutâmico & 7,06 & 0,31 & 16,74 & 0,46 \\
Prolina & 2,87 & 0,27 & 6,86 & 0,41 \\
Glicina & 3,17 & 0,07 & 3,00 & 0,08 \\
Alanina & 5,33 & 0,14 & 5,42 & 0,18 \\
Valina & 4,12 & 0,10 & 6,00 & 0,14 \\
Metionina & 1,36 & 0,35 & 2,24 & 0,21 \\
Isoleucina & 2,86 & 0,33 & 4,72 & 0,10 \\
Leucina & 4,10 & 0,12 & 7,94 & 0,12 \\
Tirosina & 1,21 & 2 valores & 2,62 & 0,76 \\
Fenilalanina & 2,48 & 2 valores & 4,16 & 0,10 \\
Histidina & 1,58 & 0,08 & 2,23 & 0,04 \\
Lisina & 4,07 & 0,17 & 6,23 & 0,05 \\
Triptofano & -- & -- & -1, & -1 \\
Arginina & 5,50 & 2 valores & 4.31 & 2 valores \\
\hline Total & 77,74 & & 89,81 & \\
\hline & & & & \\
\hline
\end{tabular}

A Tabela 7 mostra os teores de aminoácidos essenciais da proteína do coração in natura, da sopa da coração da palmeira e da proteína do ovo. O coração in natura e a sopa de coração da palmeira foram deficientes em quase todos os aminoácidos, exceto em histidina e treonina, quando comparados à proteína do ovo, considerada de alta qualidade. Quanto as necessidades básicas do ser humano (Tabela 7), pôde-se notar que a sopa de coração da palmeira supre as necessidades de aminoácidos essenciais de crianças em torno de dois anos e de 10 a 12 anos. Esses resultados comprovam apenas que a sopa de coração da palmeira possui boa quantidade de aminoácidos, o que reforça a viabilidade da utilização desse formulado na merenda escolar.

A composição mineral do coração da palmeira in natura (Tabela 8) foi inferior à do palmito in natura, excetuando-se os teores de magnésio, potássio, cobre, zinco, ferro e sódio (mesma concentração). A maior diferença entre palmito e coração da palmeira foi nos minerais manganês $(27,95$ e 7,73 , respectivamente) e zinco $(78,60$ e 202,90, respectivamente). Quando processados (Tabela 9), a composição mineral do coração da palmeira foi menor que a do palmito em fósforo, cálcio, manganês e cobre; o teor de potássio foi praticamente igual; e os demais minerais tiveram concentrações maiores no coração. A possivel influência do clima e solo sobre as características gerais do palmito tem sido aventada de longa data por pesquisadores e agricultores [4]. Pela lógica, a composição do solo deve influir sobremaneira na composição do próprio palmito e nele incutir características peculiares de textura, maciez, cor, composição mineral etc. No entanto, o sinergismo existente entre os fatores climáticos, edáficos e fisiológicos é bastante complexo e exige, para compreendê-lo, estudos específicos.

TABELA 7. Padrões de requerimento de aminoácidos, comparados com a composição de proteínas do ovo, o coração da palmeira in natura e a sopa de coração da palmeira pupunha

\begin{tabular}{|c|c|c|c|c|c|c|c|}
\hline \multirow[b]{2}{*}{ Aminoácidos } & \multicolumn{7}{|c|}{ Padrão de requerimento gaa $/ 100 \mathrm{~g}$ de proteínas ${ }^{a}$ por grupo de idade } \\
\hline & $\begin{array}{c}\text { Lactentes } \\
(3-4 \mathrm{~m})\end{array}$ & $\sim 2$ anos & $\begin{array}{r}10-12 \\
\text { anos }\end{array}$ & Adultos & $\begin{array}{l}\text { Ovo de } \\
\text { galinha }\end{array}$ & $\begin{array}{l}\text { Coração } \\
\text { in na tura }\end{array}$ & $\begin{array}{l}\text { Sopa de } \\
\text { coraçãc }\end{array}$ \\
\hline Histidina & 1,6 & $(1,9)^{\mathrm{b}}$ & $(1,9)^{b}$ & $(1,1)^{\mathrm{b}}$ & 2,2 & 1,58 & 2,23 \\
\hline Isoleucina & 4,0 & 2,8 & 2,8 & 1,3 & 5,4 & 2,86 & 4,72 \\
\hline Leucina & 9,3 & 6,6 & 4,4 & 1,9 & 8,6 & 4,10 & 7,94 \\
\hline Lisina & 6,0 & 5,8 & 4,4 & 1,6 & 7,0 & 4,07 & 6,23 \\
\hline Treonina & 5,0 & 3,4 & 2,8 & 0,9 & 4,7 & 2,86 & 3,90 \\
\hline Triptófano & 1,0 & 1,1 & $(0,9)^{b}$ & 1,7 & 1,7 & $-\ldots$ & $\ldots$ \\
\hline Valina & 5,4 & 3,5 & 2,5 & 5,5 & 6,6 & 4,12 & 6,00 \\
\hline
\end{tabular}

TABELA 8. Composição mineral média do palmito e do coração da palmeira pupunha in natura

\begin{tabular}{lcc}
\multicolumn{1}{c}{ Elementos } & Palmito & Coração da palmeira \\
\hline Fósforo (\%) & 0,550 & 0,400 \\
Cálcio (\%) & 0,440 & 0,150 \\
Magnésio (\%) & 0,270 & 0,370 \\
Sódio (\%) & 0,012 & 0,012 \\
Potássio (\%) & 2,650 & 2,750 \\
Manganês (ppm) & 27,950 & 7,730 \\
Cobre (ppm) & 12,030 & 12,960 \\
Zinco (ppm) & 78,600 & 202,900 \\
Ferro (ppm) & 25,910 & 33,320
\end{tabular}

TABELA 9. Composição mineral média do palmito e do coração da palmeira pupunha processados

\begin{tabular}{lcc}
\multicolumn{1}{c}{ Elementos } & Palmito & Coração da palmeira \\
\hline Fósforo (\%) & 0,520 & 0,260 \\
Cálcio (\%) & 0,270 & 0,190 \\
Magnésio (\%) & 0,130 & 0,150 \\
Sódio (\%) & 3,460 & 3,840 \\
Potássio (\%) & 1,610 & 1,600 \\
Manganês (ppm) & 14,270 & 7,140 \\
Cobre (ppm) & 9,250 & 7,400 \\
Zinco (ppm) & 49,400 & 110,600 \\
Ferro (ppm) & 9,250 & 16,660
\end{tabular}

Houve algumas diferenças do palmito e coração da palmeira processados em relação à sopa-creme constituída destes produtos (Tabela 10). Foram verificadas perdas em relação aos teores de magnésio, potássio, manganês, cobre e zinco entre o palmito e o coração da palmeira processados e quando sob forma de sopa-creme.

Como pôde ser observado pelo exame das tabelas descritas, o coração da palmeira não deve ser considera- 
do um subproduto da produção do palmito, sem nenhum significado nutricional. Vale ressaltar o alto teor de zinco presente tanto no palmito como no coração da palmeira. Nos seres humanos, os sinais e sintomas de deficiência de zinco dietético compreendem retardo no crescimento e desenvolvimento e aumento da incidência de complicações na gravidez, além de anomalias imunológicas, dificil cicatrização, dermatites e prejuízo nas funções neurofisiológicas [8].

TABELA 10. Composição mineral média da sopa-creme de palmito e da sopa-creme de coração da palmeira pupunha

\begin{tabular}{lcc}
\multicolumn{1}{c}{ Elementos } & Palmito & Coração da palmeira \\
\hline Fósforo (\%) & 0,520 & 0,460 \\
Cálcio (\%) & 0,400 & 0,330 \\
Magnésio (\%) & 0,054 & 0,059 \\
Sódio (\%) & 3,630 & 3,870 \\
Potássio (\%) & 1,050 & 1,070 \\
Manganês (ppm) & 4,160 & 4,200 \\
Cobre $(\mathrm{ppm})$ & 2,780 & 2,800 \\
Zinco $(\mathrm{ppm})$ & 34,100 & 43,400 \\
Ferro $(\mathrm{ppm})$ & 11,110 & 18,500
\end{tabular}

\section{4 - CONCLUSÕES}

A partir dos resultados obtidos neste trabalho pôdese verificar que o coração da palmeira pouco difere em relação ao palmito em termos de composição química. Dessa forma, torna-se viável a utilização do coração da palmeira na alimentação humana em substituição ao palmito sob forma de sopa-creme para a merenda escolar e outras aplicações, como molhos para pizza e recheios para pastel, além de poder vir a ser um veículo de redução da atual atividade extrativista predatória que esta palmeira vem sofrendo.

\section{5 - REFERÊNCIAS BIBLIOGRÁFICAS}

[1] ASSOCIATION OF OFFICIAL AGRICULTURAL CHEMISTS AOAC. Official agricultural chemists. 13.ed. Washington, D.C., 1980.

[2] ASSOCIATION OF OFFICIAL AGRICULTURAL CHEMISTS AOAC. Official agricultural chemists. 15.ed. Washington, D.C., 1990.

[3] CURSO de treinamento para gestores municipais para merenda escolar. Belo Horizonte. FAE - Fundação de Atendimento ao Estudante, 1996 (Anotações).

[4] FERREIRA, V. L. P., BOVI, M. L. A., CARVALHO, C. R. L. et al. Composição química e curvas de titulação de acidez do palmito pupunha (Bactris gasipaes H.B.K.) de diversas localidades. Coletânea do Instituto de Tecnologia de Alimentos, v. 20, p.96-104, 1990.

[5] FERREIRA, V. L. P., GRANER, M., BOVI, M. L. A. et al. Comparação entre os palmitos de Guilielma gasipaes Bailey (pupunha) e Euterpe esdulis Mart. (juçara). I- Avaliaçòes físicas, organolépticas e bioquímicas. Coletânea do Instituto de Tecnologia de Alimentos, v. 12, p.273-282, 1981-1982.

[6] FREITAS, R. J. S., FUGMAN, H. A. J. Componentes minerais do palmito (Euterpe edulis Mart.). Boletim do CEPPA, v. 8, n.1, p.35-39. 1990.

[7] INSTITUTO BRASILEIRO DE GEOGRAFIA E ESTATÍSTICA IBGE. Tabela de composição de alimentos: estudo nacional da despesa familiar (ENDEF). Rio de Janeiro, 1977. V. 3. 533p.

[8] NATIONAL RESEARCH COUNCIL. Recommended dietary allowances (RDA). 10. ed. Washington, 1989. 279p.

[9] NOGUEIRA, J. N. Palmito: produção, pré-processamento e transformação agroindustrial. São Paulo: Fundação de Estudos Agrários "Luiz de Queiroz" (FEALQ), 1984. 66p.

[10] NORMAS Analíticas do Instituto Adolfo Lutz 3. ed. São Paulo, 1985. v. 1, 535p. 